\title{
Direct Power Control of Grid-Connected Wound Rotor Induction Machine Without Rotor Position Sensors
}

\author{
Rajib Datta and V. T. Ranganathan, Senior Member, IEEE
}

\begin{abstract}
A method is presented for fast response control of the torque and flux of a grid connected wound rotor induction machine fed by back to back connected voltage source inverters on the rotor side. It is based on the measurement of active and reactive power on the grid side where voltages and currents are alternating at fixed frequency. The active and reactive powers are made to track references using hysteresis controllers. The method eliminates the need for rotor position sensing and gives excellent dynamic performance, as shown by simulation and experimental results from a variable speed constant frequency induction generator system. It is also capable of starting on the fly. It is thus an attractive sensorless control method for drive as well as generator applications.
\end{abstract}

Index Terms-Induction motors, power control, reactive power control, sensorless control, torque control, variable speed constant frequency applications, variable speed drives, wind power generation.

\section{NOMENCLATURE}

$\psi_{s}, \psi_{r}, \psi_{m} \quad$ Stator flux, rotor flux and air-gap flux, respectively.

$i_{s}, i_{r}$

$u_{s}, u_{r}$

$i_{s q}, i_{s d}$

$i_{r q}, i_{r d}$

$i_{m s}$

$\delta_{p}$

$\omega_{s}$

$L_{0}$

$\sigma_{s}, \sigma_{r}$

$P_{s}, P_{r}$

$Q_{s}, Q_{r}$

$P, Q$

$m_{d}$ Stator current and rotor current, respectively. Stator voltage and rotor voltage, respectively. Active component and reactive component of stator current, respectively.

Active component and reactive component of rotor current, respectively.

Stator flux magnetizing current.

Angle between the stator flux and rotor flux.

Stator frequency.

Magnetizing inductance.

Stator and rotor leakage factors, respectively.

Stator and rotor active powers, respectively.

Stator and rotor reactive powers, respectively. Total active and reactive powers, respectively. Machine torque.

\section{INTRODUCTION}

$\mathbf{I}$ $\mathrm{N}$ RECENT years, there has been an increased attention toward wind power generation. Conventionally, grid-connected cage rotor induction machines are used as wind gen-

Manuscript received March 17, 2000; revised November 1, 2000. Recommended by Associate Editor G. K. Dubey.

The authors are with the Department of Electrical Engineering, Indian Institute of Science, Bangalore 560 012, India.

Publisher Item Identifier S 0885-8993(01)04035-2. erators at medium power level. When connected to the constant frequency network, the induction generator runs at nearsynchronous speed drawing the magnetizing current from the mains, thereby resulting in constant speed constant frequency (CSCF) operation. However, the power capture due to fluctuating wind speed can be substantially improved if there is flexibility in varying the shaft speed.

In such variable speed constant frequency (VSCF) application rotor side control of grid-connected wound rotor induction machine is an attractive solution. In the system under consideration, the stator is directly connected to the three phase grid and the rotor is supplied by two back-to-back PWM converters (Fig. 1). Such an arrangement provides flexibility of operation in subsynchronous and supersynchronous speeds both in the generating and motoring modes. The rating of the power converters used in the rotor circuit is substantially lower than the machine rating and is decided by the range of operating speed. Of the two converters, the function of the line side converter is to regulate the dc bus voltage and act as unity power factor interface to the grid for either direction of power flow. The machine side converter has to control the torque and flux of the machine or alternatively the active and reactive powers. The present work is concerned with the control of the machine side converter.

The conventional approach for independent control of active and reactive powers handled by the machine is stator flux oriented vector control with rotor position sensors [1], [2]. The performance of the system in this case depends on the accuracy of computation of the stator flux and the accuracy of the rotor position information derived from the position encoder. Alignment of the position sensor is moreover, difficult in a doubly-fed wound rotor machine.

Position sensorless vector control methods have been proposed by several research groups in the recent past [3]-[6]. In [3], a dynamic torque angle controller is proposed. This method uses integration of the PWM rotor voltage to compute the rotor flux; hence satisfactory performance cannot be achieved at or near synchronous speed. Most of the other methods proposed make use of the measured rotor current and use coordinate transformations for estimating the rotor position [4]-[6]. Varying degree of dependence on machine parameters is observed in all these strategies.

Alternative approaches to field oriented control such as direct self control (DSC) [7] and direct torque control (DTC) [8], [9] have been proposed for cage rotor induction machines. In these strategies, two hysteresis controllers, namely a torque controller and a flux controller, are used to determine the instantaneous 


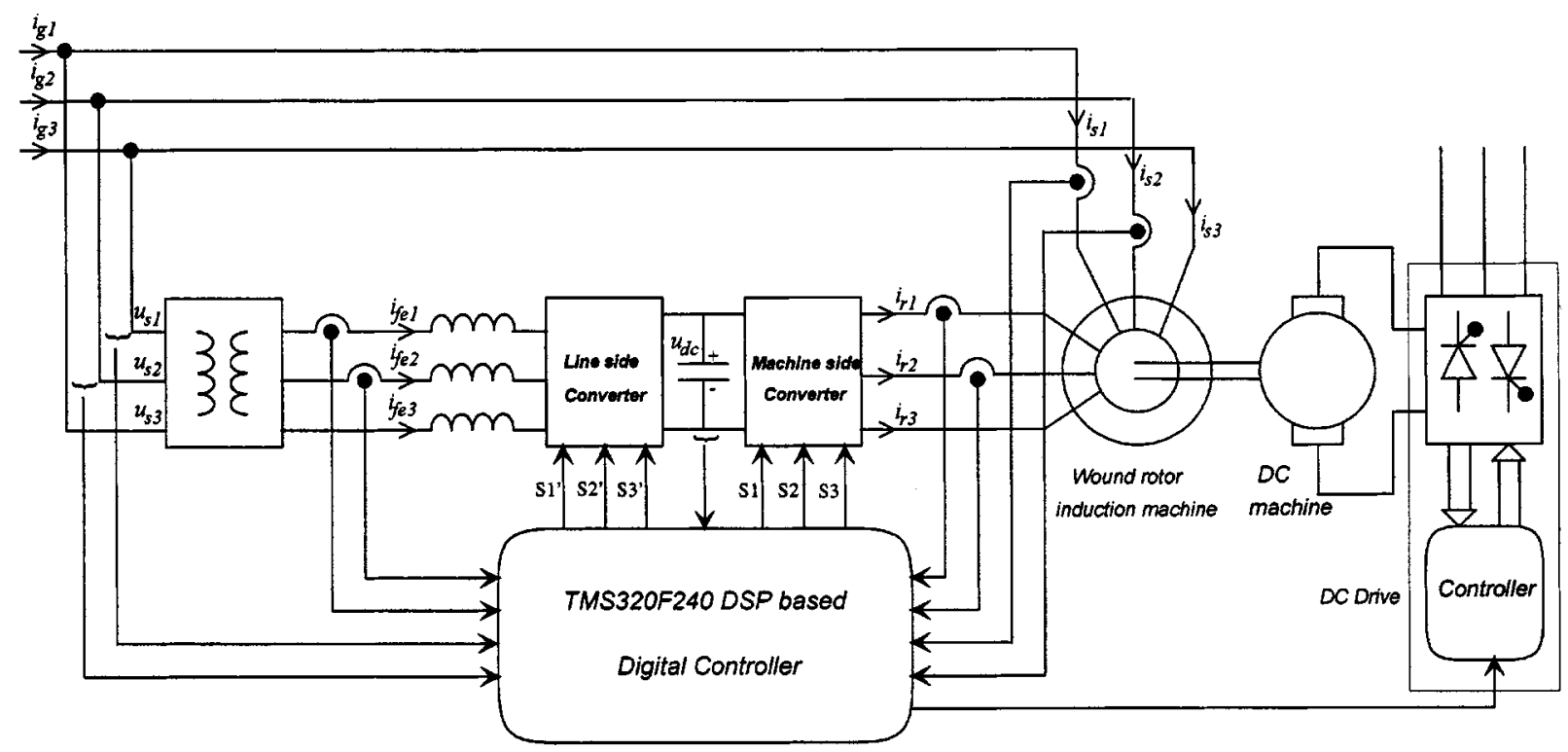

Fig. 1. Schematic block diagram of the experimental setup.

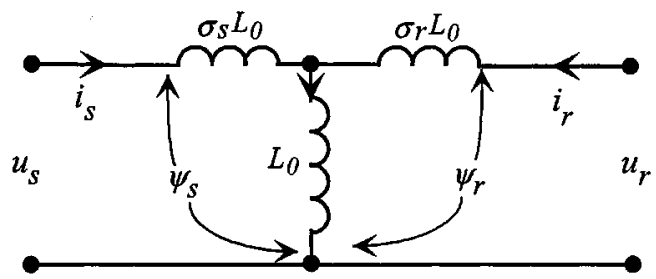

Fig. 2. Approximate equivalent circuit.

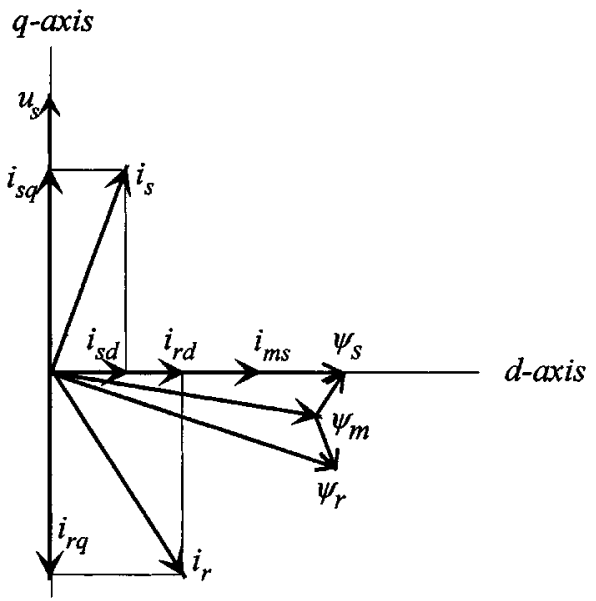

Fig. 3. Phasor diagram.

switching state for the inverter. These methods of control are computationally very simple and do not require rotor position information. However, the application of such techniques to the control of wound rotor induction machine has not been considered so far.

In this paper, a recently developed algorithm [10], [11] for independent control of active and reactive powers with high dynamic response in case of a wound rotor induction machine is described. The instantaneous switching state of the rotor side converter is determined based on the active and reactive powers measured in the stator circuit. Thus, unlike existing DTC techniques, measurements are carried out at one terminal of the machine whereas the switching action is carried out at another terminal. Here the directly-controlled quantities are the stator active and reactive powers; hence, the algorithm is referred to as direct power control in the text. The proposed algorithm also differs from conventional DTC in that it does not use integration of PWM voltages. Hence, it can work stably even at zero rotor frequency. The method is inherently position sensorless and does not depend on machine parameters like stator/rotor resistance. It can be applied to VSCF applications like wind power generation as well as high power drives.

The concept of direct power control is first introduced and details of the control strategy are discussed. The laboratory experimental setup on which the algorithm is implemented is described. Relevant simulation and experimental results are presented to validate the performance of the proposed method.

\section{CONCEPT OF Direct POWER CONTROL}

The basic concept of direct control of active and reactive powers can be appreciated from the phasor diagrams based on the equivalent circuit of the doubly-fed machine as shown in Fig. 2. From the phasor diagram in Fig. 3 it is noted that the component $i_{s q}$ of the stator current has to be controlled to control the stator active power $P_{s}$ and $i_{s d}$ has to be controlled to control the stator reactive power $Q_{s}$. This is achieved in turn by controlling the rotor currents $i_{r q}$ and $i_{r d}$, respectively, in conventional field oriented control strategy.

The effect of injection of these rotor currents on the air-gap and rotor fluxes can be derived by subtracting and adding the respective leakage fluxes. The variation of the rotor flux with variations in the active and reactive power demand is shown in Fig. 4(a) and (b). In Fig. 4(a) $i_{r d}=0$, i.e., the reactive power is fed completely from the stator side. Under this condition if $i_{r q}$ is varied from 0 to full load, the locus of $\underline{\psi}_{r}$ varies along A-B which indicates a predominant change in angle $\delta$ between $\psi_{s}$ 


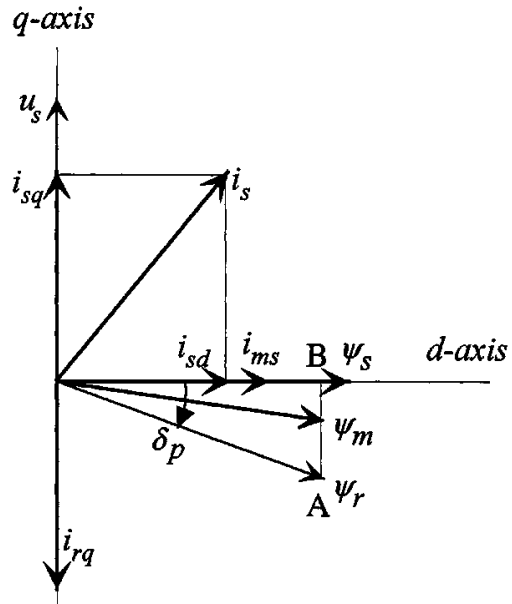

(a)

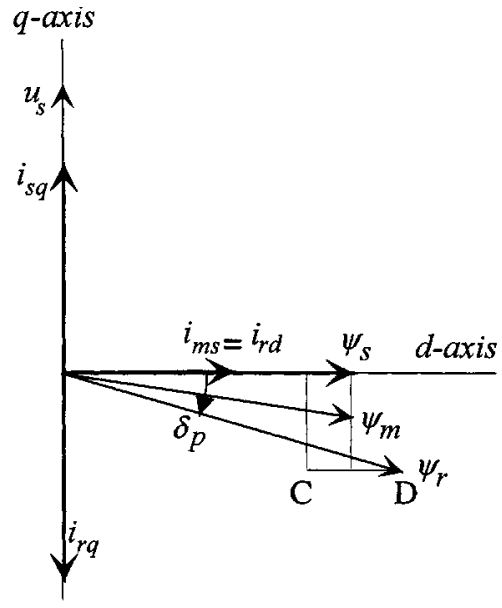

(b)

Fig. 4. Phasor diagram showing variations in rotor flux with change in active and reactive power.

and $\psi_{r}$, whereas the magnitude of $\psi_{r}$ does not change appreciably. In other words, a change in the angle $\delta$ would definitely result in a change in the active power handled by the stator in a predictable fashion.

In Fig. 4(b) the stator active power demand is maintained constant so that $i_{r q}$ is constant and $i_{r d}$ is varied from 0 to the rated value of $i$. Here the locus of $\underline{\psi}_{r}$ varies along C-D, resulting in a predominant change in magnitude of $\psi_{r}$, whereas the variation of $\delta$ is small. Therefore, the reactive power drawn from the grid by the stator can be reduced by increasing the magnitude of the rotor flux and vice-versa. It may be noted that the phasor diagrams as indicated in Fig. 4(a) and (b) remain the same irrespective of the reference frame; the frequency of the phasors merely changes from one reference frame to the other. It can be concluded from the above discussion that

i) The stator active power can be controlled by controlling the angular position of the rotor flux vector.

ii) The stator reactive power can be controlled by controlling the magnitude of the rotor flux vector.

These two basic notions are used to determine the instantaneous switching state of the rotor side converter to control the active and reactive power as discussed in the following section.

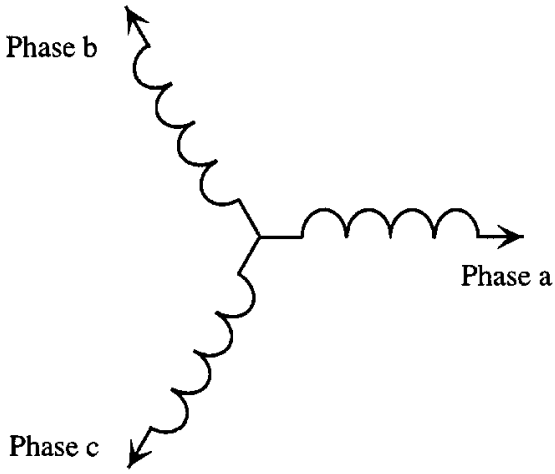

(a)

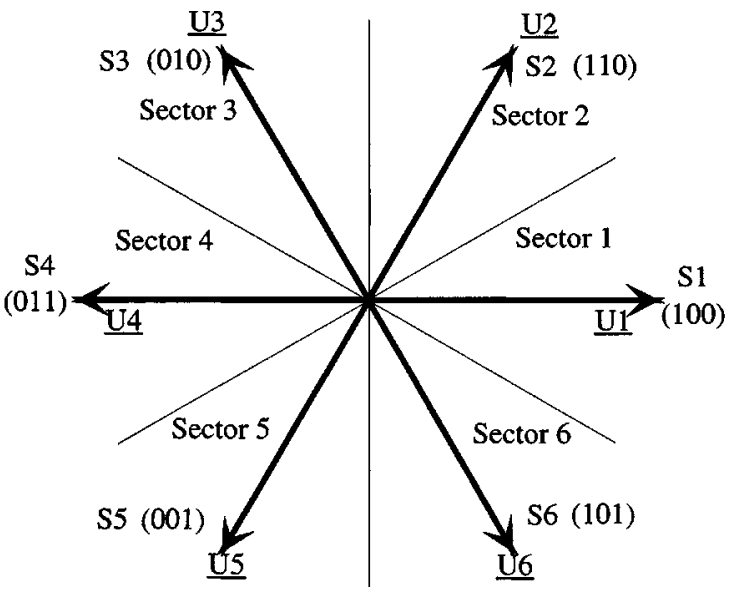

(b)

Fig. 5. (a) Orientation of the rotor winding in space with respect to which the voltage space phasors are drawn and (b) voltage space phasors.

\section{Voltage Vectors AND Their EFFECTS}

Assuming that the orientation of the three phase rotor winding in space at any instant of time is as given in Fig. 5(a), the six active switching states $\mathrm{S} 1, \mathrm{~S} 2 \ldots \mathrm{S} 6$ would result in the voltage space vectors $\underline{U 1}, \underline{U 2} \cdots \underline{U 6}$ [Fig. 5(b)] at that instant. In order to make an appropriate selection of the voltage vector the space phasor plane is first subdivided into six $60^{\circ}$ sectors $1,2 \ldots 6$. The instantaneous magnitude and angular velocity of the rotor flux can now be controlled by selecting a particular voltage vector depending on its present location. The effect of the different vectors as reflected on the stator side active and reactive powers, when the rotor flux is positioned in Sector 1 is illustrated in the following subsections.

\section{A. Effect of Active Vectors on Active Power}

Considering anti clockwise direction of rotation of the flux vectors in the rotor reference frame to be positive, it may be noted that $\psi_{s}$ is ahead of $\psi_{r}$ in motoring mode of operation and $\psi_{s}$ is behind $\psi_{r}$ in generating mode. This is illustrated in Fig. 6 (a) and (b) respectively. In the rotor reference frame the flux vectors rotate in the positive direction at subsynchronous speeds, remain stationary at synchronous speed and start rotating in the negative direction at supersynchronous speeds.

Assuming that the rotor flux is positioned in Sector 1, application of voltage vectors $\underline{U 2}$ and $\underline{U 3}$ accelerates $\psi_{r}$ in the positive 


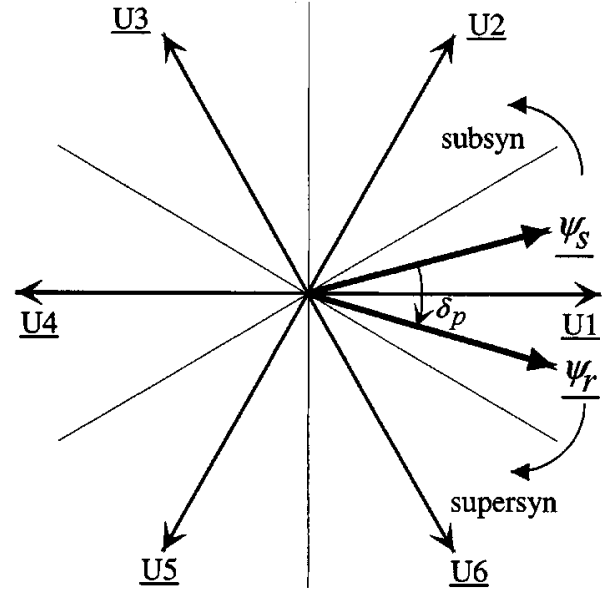

(a)

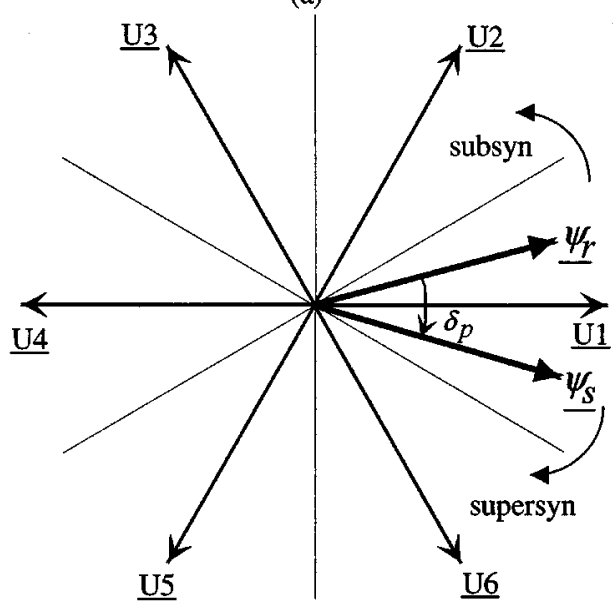

(b)

Fig. 6. Flux vectors in (a) motoring mode and (b) generating mode.

direction. In the motoring mode of operation, this reduces the angular separation between the two fluxes resulting in a reduction of active power drawn by the stator. In the generating mode of operation, application of vectors $U 2$ and $U 3$ results in an increase in angular separation between the two and thereby an increase in the active power generated by the stator. $\left(P_{s}\right.$ being negative for generation, application of $U 2$ and $U 3$ still results in a reduction of positive active power.) Similarly it can be seen that the effect of $\underline{U 5}$ and $U 6$ on the active power would be exactly opposite to that of $\underline{U 2}$ and $\underline{U 3}$ in both the motoring and generating modes.

Power drawn by the stator being taken as positive and power generated being taken as negative, it may therefore, be concluded that, if the rotor flux is in the $k$ th sector, where $k=1,2,3 \ldots 6$, application of vectors $U(k+1)$ and $U(k+2)$ would result in a reduction in the stator active power and application of vectors $U(k-1)$ and $U(k-2)$ would result in an increase in the stator active power.

\section{B. Effect of Active Vectors on Reactive Power}

From the phasor diagrams Fig. 4(a) and (b) it can be seen that the reactive power drawn by the stator depends upon the component of $\psi_{r}$ along $\psi_{s}$ i.e., $\psi_{r d}$. The angle between $\psi_{s}$ and $\psi_{r}$ i.e., $\delta$ being small, the magnitude of $\underline{\psi}_{r}$ is approximately equal to $\psi_{r d}$. Therefore, when the rotor flux vector is located in
Sector 1, voltage vectors $\underline{U 1}, \underline{U 2}$, and $\underline{U 6}$ increase the magnitude of $\psi_{r}$ whereas, $\underline{U 3}, \underline{U 4}$, and $\underline{U 5}$ reduce it. This holds good irrespective of whether the machine is operating in motoring or generating mode. An increase in magnitude of $\psi_{r}$ indicates an increased amount of reactive power being fed from the rotor side and hence, a reduction in the reactive power drawn by the stator resulting in an improved stator power factor. A decrease in magnitude of $\underline{\psi}_{r}$ amounts to lowering of the stator power factor.

As a generalization it can therefore, be said that if the rotor flux resides in the $k$ th sector, switching vectors $U(k), U(k+1)$, and $U(k-1)$ reduce the reactive power drawn from the stator side and $U(k+2), U(k-2), U(k+3)$ increase the reactive power drawn from the stator side.

\section{Effect of Zero Vector on Active Power}

The effect of the zero vectors is to stall the rotor flux without affecting its magnitude. This results in an opposite effect on the stator active power in subsynchronous and supersynchronous modes of operation.

In subsynchronous motoring, application of a zero vector increases $\delta$ as $\psi_{s}$ keeps rotating in the positive direction at slip speed. Above the synchronous speed, $\psi_{s}$ rotates in the counter clockwise direction thereby reducing $\delta$. Hence active power drawn by the stator increases for subsynchronous operation and decreases for supersynchronous operation. Active power generated being negative, the same conclusion holds true for the generating modes as well.

\section{Effect of Zero Vector on Reactive Power}

Since a zero vector does not change the magnitude of the rotor flux its effect on the reactive power is rather small. Nevertheless, there is some small change in $Q_{s}$; its effect being dependent on whether the angle between the stator and rotor fluxes increases or decreases due to the application of a zero vector. An increase in angular separation between the two fluxes reduces $\psi_{r d}$ resulting in an increment of $Q_{s}$ drawn from the stator side. The converse is true when $\delta$ reduces.

It is observed that the change in $Q_{s}$ due to the application of the zero vector is different in all the 4 modes of operation. This is summarized in Table I.

\section{CONTROL AlgORIthM}

With the inferences drawn in the previous section it is possible to switch an appropriate voltage vector in the rotor side at any given instant of time to increase or decrease the active or reactive power in the stator side. Therefore, any given references for stator active and reactive powers can be tracked within a narrow band by selecting proper switching vectors for the rotor side converter. This is the basis of the direct power control strategy. The details of the control algorithm are discussed in the following subsections.

It should be noted that the torque reference for the machine is decided by an outer loop for either motoring or generating application. The reference for the stator power can, therefore, be calculated as

$$
P_{s}^{*}=m_{d}^{*} \cdot \omega_{s}
$$


TABLE I

EfFect of Zero Vector on Active and Reactive Power

\begin{tabular}{c|c|c}
\hline Speed & Motoring & Generating \\
\hline Subsynchronous & $\delta_{p} \uparrow \Rightarrow \psi_{r d} \downarrow \Rightarrow Q_{s} \uparrow$ & $\delta_{p} \downarrow \Rightarrow \psi_{r d} \uparrow \Rightarrow Q_{s} \downarrow$ \\
\hline Supersynchronous & $\delta_{p} \downarrow \Rightarrow \psi_{r d} \uparrow \Rightarrow Q_{s} \downarrow$ & $\delta_{p} \uparrow \Rightarrow \psi_{r d} \downarrow \Rightarrow Q_{s} \uparrow$ \\
\hline
\end{tabular}

Note: $\uparrow$ denotes increase, $\downarrow$ denotes decrease

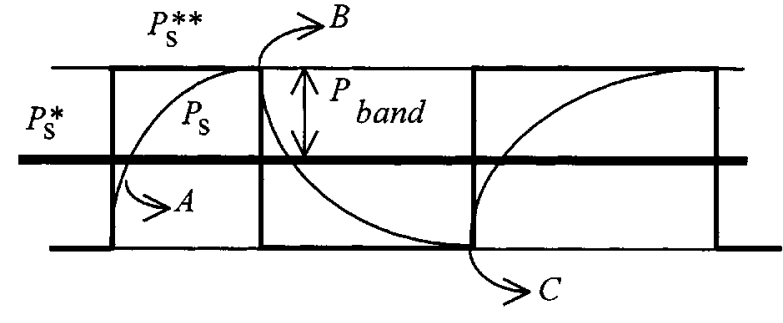

Fig. 7. Hysteresis control of active power.

$Q_{s}^{*}$ is set according to the desired power factor at the stator terminals.

\section{A. Measurement of Stator Active and Reactive Power}

The active and reactive powers on the stator side can be directly computed from the stator currents and voltages. Assuming a balanced three phase three wire system, only two currents and two voltages need to be measured. The active and reactive powers can be expressed as

$$
\begin{aligned}
& P_{s}=\frac{2}{3}\left(u_{s a} i_{s a}+u_{s \beta} i_{s \beta}\right) \\
& Q_{s}=\frac{2}{3}\left(u_{s \beta} i_{s a}-u_{s a} i_{s \beta}\right)
\end{aligned}
$$

where

$$
\begin{aligned}
u_{s a} & =\frac{3}{2} u_{s 1} \\
u_{s \beta} & \frac{\sqrt{3}}{2}\left(u_{s 1}+2 u_{s 2}\right)
\end{aligned}
$$

and,

$$
\begin{aligned}
& i_{s a}=\frac{3}{2} i_{s 1} \\
& i_{s \beta}=\frac{\sqrt{3}}{2}\left(i_{s 1}+2 i_{s 2}\right) .
\end{aligned}
$$

\section{B. Defining References and Errors}

As shown in Fig. 7, $P_{s}^{*}$ is the reference for stator active power. The actual power $P_{s}$ is to be controlled to stay within a band of width $P_{\text {band }}$ about $P_{s}^{*}$. This is achieved by defining an auxiliary reference $P_{s}^{* *}$ and switching as per the following logic.

$$
\begin{aligned}
& P_{\text {err }}=P_{s}^{* *}-P_{s} \\
& \begin{array}{ll}
\text { if }\left(P_{\text {err }}>0\right) & P_{s}^{* *}=P_{s}^{*}+P_{\text {band }} \\
\text { else } & P_{s}^{* *}=P_{s}^{*}-P_{\text {band }} .
\end{array}
\end{aligned}
$$

In a similar manner the error and reference for the reactive power can be written as

$$
\begin{aligned}
& Q_{e r r}=Q_{s}^{* *}-Q_{s} \\
& \text { if }\left(Q_{e r r}>0\right) \quad Q_{s}^{* *}=Q_{s}^{*}+Q_{b a n d} \\
& \text { else } \quad Q_{s}^{* *}=Q_{s}^{*}-Q_{b a n d}
\end{aligned}
$$

\section{Switching Vector Selection}

In order to determine the appropriate switching vector at any instant of time, the errors in $P_{s}$ and $Q_{s}$, and the sector in which the rotor flux vector is presently residing are taken into consideration. Thus the following two switching tables for active vector selection can be generated. Tables II and III correspond to negative $P_{e r r}$ and positive $P_{e r r}$, respectively.

If the rotor side converter is switched in accordance to these tables it is possible to control the active and reactive powers in the stator side within the desired error bands. But the use of active vectors alone would result in nonoptimal switching of the converter and also a higher switching frequency.

By considering the effect of the zero vector on active and reactive powers, the logic for selecting the zero vector can be summarized as in Table IV. During subsynchronous motoring mode of operation, the application of a zero vector will increase $Q_{s}$ as seen from Table I. As $\delta_{p}$ increases under this condition, $P_{s}$ also increases. Hence, when the errors in $Q_{s}$ and $P_{s}$ are positive, a zero vector is applied to effect an increment in both the stator active and reactive powers and thereby bring down the errors. The other entries in the table can be worked out in a similar manner. Whenever a zero vector has to be applied, the one nearest to the present active vector is selected to minimize the number of switchings.

Also, it is observed that the effect of the zero state on $P_{s}$ is opposite in the subsynchronous and supersynchronous modes of operation. This criterion is used in detecting the transition from subsynchronous to supersynchronous operation and vice-versa.

\section{SECtOR IDENTIFICATION OF ROTOR FLuX}

In order to implement the switching algorithm the present sector of the rotor flux has to be identified. The exact position of the rotor flux space phasor within the sector is not of importance as far as the selection of the switching vectors is concerned.

The proposed method of sector identification is based on the direction of change in $Q_{s}$ when a particular switching vector is applied. The concept is illustrated by the following example. Suppose that the present position of the rotor flux is in Sector 1 and it is moving in the positive direction (corresponding to subsynchronous operation). Therefore, application of switching states $\mathrm{S} 2$ and $\mathrm{S} 6$ results in a reduction of $Q_{s}$ and application of S3 and S5 results in an increase of $Q_{s}$. When the rotor flux vector crosses over to Sector 2, the effect of states S3 and S6 on $Q_{s}$ would reverse. Vector $\underline{U 3}$ would now act to reduce $Q_{s}$ instead of increasing it. Similarly the effect of vector $\underline{U 6}$ on $Q_{s}$ would also be opposite. These reversals in the direction of change of $Q_{s}$, when a particular vector is applied, can be detected and a decision for sector change may be taken on this 
TABLE II

Selection of Active Switching States When $\left(P_{\text {er }}<=0\right)$

\begin{tabular}{c|c|c|c|c|c|c}
\hline & Sector 1 & Sector 2 & Sector 3 & Sector 4 & Sector 5 & Sector 6 \\
\hline Qerr $>0$ & $\mathrm{~S} 3$ & $\mathrm{~S} 4$ & $\mathrm{~S} 5$ & $\mathrm{~S} 6$ & $\mathrm{~S} 1$ & $\mathrm{~S} 2$ \\
\hline Qerr $<=0$ & $\mathrm{~S} 2$ & $\mathrm{~S} 3$ & $\mathrm{~S} 4$ & $\mathrm{~S} 5$ & $\mathrm{~S} 6$ & $\mathrm{~S} 1$ \\
\hline
\end{tabular}

TABLE III

Selection of Active Switching States When $\left(P_{\text {err }}>0\right)$

\begin{tabular}{c|c|c|c|c|c|c}
\hline & Sector 1 & Sector 2 & Sector 3 & Sector 4 & Sector 5 & Sector 6 \\
\hline Qerr $>0$ & $\mathrm{~S} 5$ & $\mathrm{S6}$ & $\mathrm{S} 1$ & $\mathrm{~S} 2$ & $\mathrm{S3}$ & $\mathrm{S4}$ \\
\hline Qerr $<=0$ & $\mathrm{~S} 6$ & $\mathrm{~S} 1$ & $\mathrm{~S} 2$ & $\mathrm{~S} 3$ & $\mathrm{~S} 4$ & $\mathrm{~S} 5$ \\
\hline
\end{tabular}

TABLE IV

CONDITION FOR SELECTION OF ZERO VeCTOR

\begin{tabular}{c|c|c}
\hline Speed & Motoring & Generating \\
\hline Subsynchronous & $Q_{e r r} \geq 0 \& \& P_{e r r} \geq 0$ & $Q_{e r r}<0 \& \& P_{e r r} \geq 0$ \\
\hline Supersynchronous & $Q_{e r r}<0 \& \& P_{e r r}<0$ & $Q_{e r r} \geq 0 \& \& P_{e r r}<0$ \\
\hline
\end{tabular}

TABLE $\mathrm{V}$

EXPECTED DiRECTION OF CHANGE IN $Q_{s}$

\begin{tabular}{l|c|c|c|c|c|c|c|c}
\hline & S0 & S1 & S2 & S3 & S4 & S5 & S6 & S7 \\
\hline Sector 1 & 0 & - & - & + & + & + & - & 0 \\
\hline Sector 2 & 0 & - & - & - & + & + & + & 0 \\
\hline Sector 3 & 0 & + & - & - & - & + & + & 0 \\
\hline Sector 4 & 0 & + & + & - & - & - & + & 0 \\
\hline Sector 5 & 0 & + & + & + & - & - & - & 0 \\
\hline Sector 6 & 0 & - & + & + & + & - & - & 0 \\
\hline
\end{tabular}

TABLE VI

DiRECTION OF CHANGE OF SECTOR

\begin{tabular}{l|c|c|c|c|c|c|c|c}
\hline & S0 & S1 & S2 & S3 & S4 & S5 & S6 & S7 \\
\hline Sector 1 & 0 & 0 & -1 & +1 & 0 & -1 & +1 & 0 \\
\hline Sector 2 & 0 & +1 & 0 & -1 & +1 & 0 & -1 & 0 \\
\hline Sector 3 & 0 & -1 & +1 & 0 & -1 & +1 & 0 & 0 \\
\hline Sector 4 & 0 & 0 & -1 & +1 & 0 & -1 & +1 & 0 \\
\hline Sector 5 & 0 & +1 & 0 & -1 & +1 & 0 & -1 & 0 \\
\hline Sector 6 & 0 & -1 & +1 & 0 & -1 & +1 & 0 & 0 \\
\hline
\end{tabular}

basis. Similarly, if the flux vector is rotating in the negative direction (supersynchronous operation) the effect of states S2 and S5 on $Q_{s}$ would change in direction when $\psi_{r}$ changes over from Sector 1 to Sector 6 . Thus in any particular direction of rotation there are two vectors which can provide the information for a change in sector. Since the rotor flux vector cannot jump through sectors the change will always be by one sector, either preceding or succeeding. In this method, even though the exact position of the flux is unknown, the sector information can be updated just by observing the changes in $Q_{s}$ due to the applied vectors. It may be noted that the effect of the vectors on $P_{s}$ would not provide a conclusive inference about the change in sector.

The expected direction of change in $Q_{s}$ due to the application of any switching state in the different sectors can be summed up as shown in Table V. It may however, be noted that in a particular sector not all vectors will be applied. For example, in sector $k$, vectors $U(k)$ and $U(k+3)$ will never be applied. These vectors would have predominant effect on the reactive power, but their effect on the active power would depend on the actual position of the rotor flux vector in the sector. In most applications there is hardly any requirement for fast transient changes in reactive power; so it is not necessary to apply the strongest vector to effect any change in $Q_{s}$. In the switching logic, therefore, only those vectors are selected which have uniform effects on $P_{s}$ and $Q_{s}$ in terms of their direction of change irrespective of the position of the rotor flux in a particular sector.

For any given vector applied in a particular sector the expected direction of change in $Q_{s}$ can be read off from Table V. The actual direction of change can be computed from the present value of $Q_{s}$ and its previous value. If the actual direction of change is opposite to the expected direction of change then a decision on change of sector is taken. Whether the sector change has to be effected in the clockwise or anti clockwise direction 


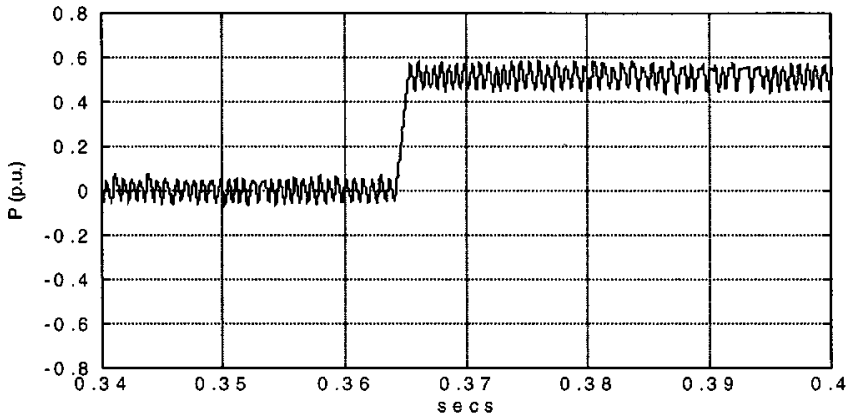

(a)

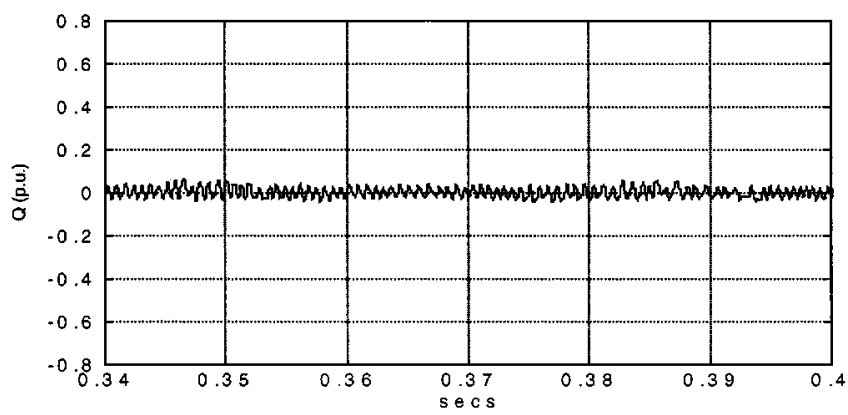

(b)

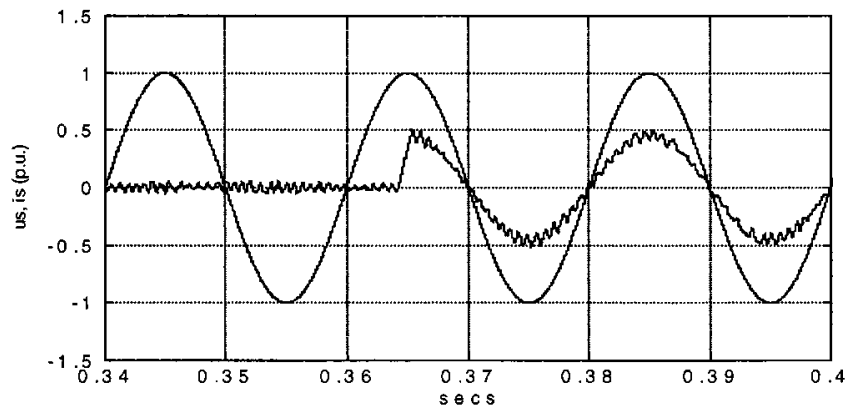

(c)

Fig. 8. Simulation results showing transient responses of $P_{s}, Q_{s}$ and corresponding $i_{s}$ due to step change in $P_{s}^{*}$ from 0 to 0.5 p.u. with $Q_{s}^{*}=0$ at $\omega=0.9$ p.u., (a) response of $P_{s}$, (b) response of $Q_{s}$, and (c) response of $i_{s}$.

depends on the applied vector and the observed change in $Q_{s}$. This information is stored in another lookup table (Table VI).

The method of sector identification is therefore, independent of any machine parameter but relies on directly measurable fixed frequency quantities. It is also independent of the rotor frequency and can work stably at or near synchronous speed.

\section{SimULATION RESULtS}

The direct power control algorithm is simulated on the MATLAB-SIMULINK platform. The transient response due to a step change in active power command $P_{s}^{*}$ from 0 to 0.5 p.u., while $Q_{s}^{*}$ is maintained at 0 is shown in Fig. 8(a) and (b). $P_{\text {band }}$ and $Q_{b a n d}$ are kept at 0.05 p.u. in this case. It is observed that $P_{s}$ reaches its set value in approximately $2 \mathrm{~ms}$. This can be the fastest possible response at a given speed because only the desired active vector is used during the transient. The response of the stator current corresponding to this step change in active power is presented in Fig. 8(c). Since the reactive power reference $Q^{*}$ is held at zero, unity power factor operation is clearly

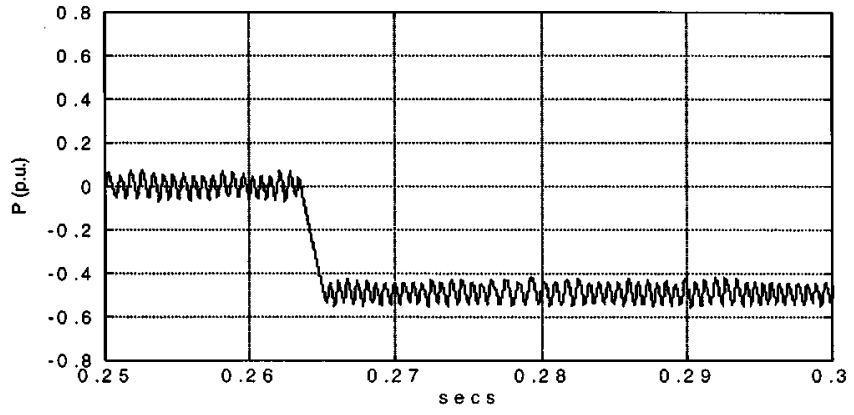

(a)

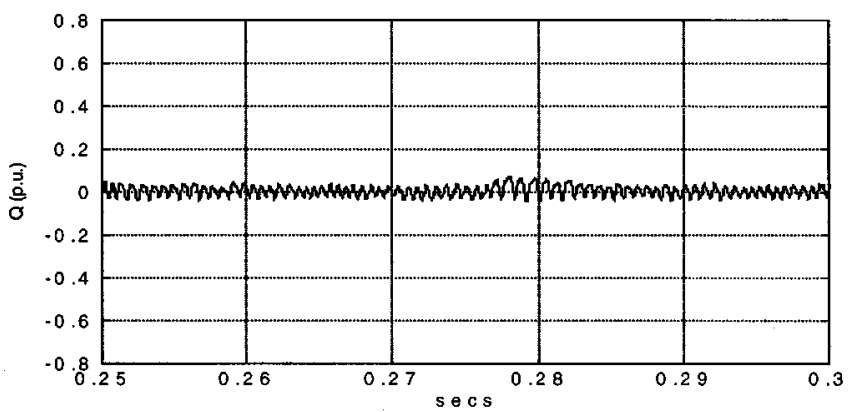

(b)

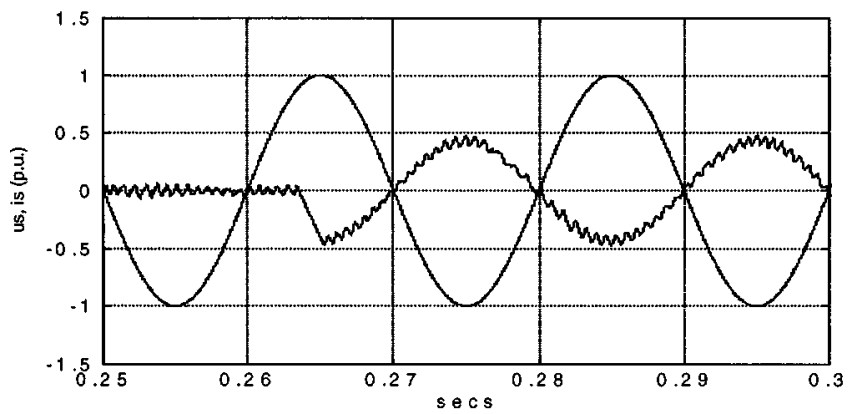

(c)

Fig. 9. Simulation results showing transient responses of $P_{s}, Q_{s}$ and corresponding $i_{s}$ due to step change in $P_{s}^{*}$ from 0 to -0.5 p.u. with $Q_{s}^{*}=0$ at $\omega=0.9$ p.u., (a) response of $P_{s}$, (b) response of $Q_{s}$, and (c) response of $i_{s}$.

observed at the stator terminals. Similar transient response for generating condition is given in Fig. 9(a)-(c).

\section{IMPLEMENTATION AND EXPERIMENTAL RESULTS}

The schematic block diagram of the laboratory experimental setup is given in Fig. 1. It consists of a $3.5 \mathrm{~kW}$ wound rotor induction machine with its stator connected to the $415 \mathrm{~V}, 50 \mathrm{~Hz}$, 3- $\phi$ power grid, and the rotor being fed by two back-to-back IGBT-based PWM converters. The setup is organized for generation operation where the torque-speed characteristics of the prime mover (such as a wind turbine) are simulated by a $5 \mathrm{hp}$ dc motor driven by a commercial four-quadrant thyristor drive. A TMS320F240 DSP based digital control platform is designed and employed for implementing the direct power algorithm. The processor runs at a clock frequency of $36 \mathrm{MHz}$ and the sampling frequency used is $56 \mu \mathrm{s}$. The software is assembly coded for fast real-time execution. For the sake of easy uniformity, the oscilloscope waveforms presented in this section are scaled in such a manner that $5 \mathrm{~V}$ represents 1 p.u. 


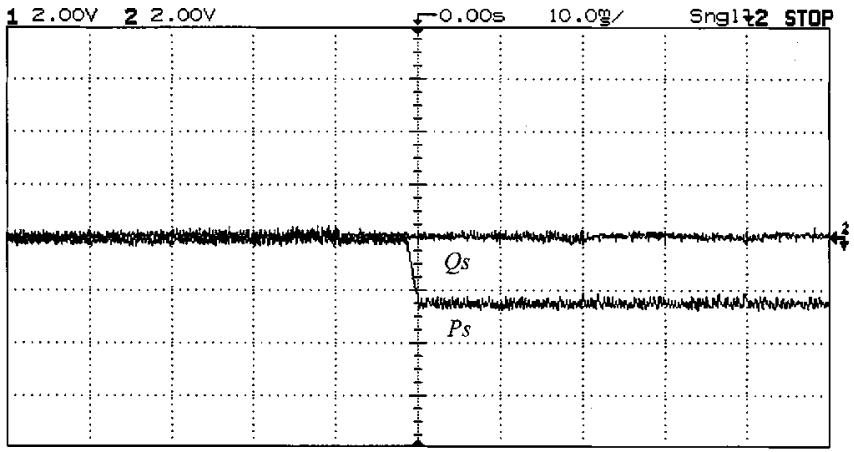

(a)

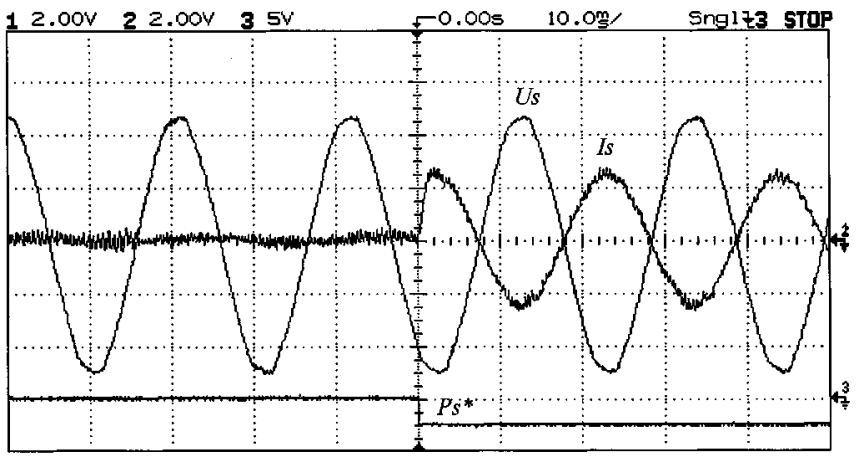

(b)

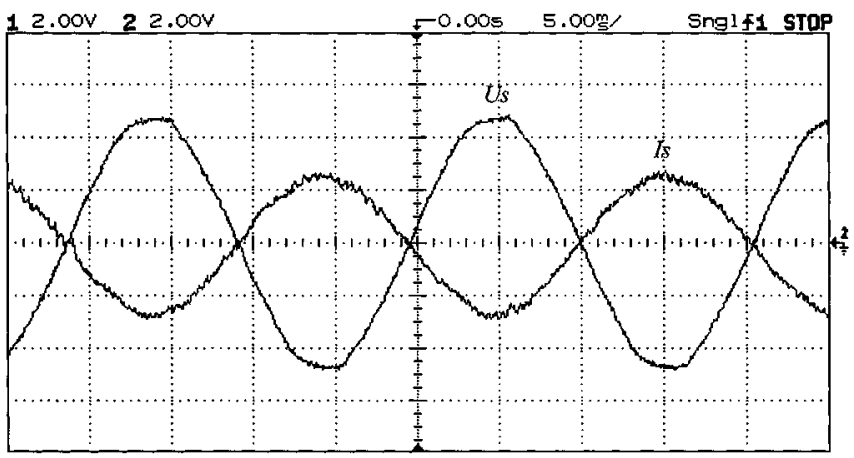

(c)

Fig. 10. (a) Experimental waveforms showing transient response of $P_{s}$ and $Q_{s}$ due to step change in $P_{s}^{*}$ from 0 to -0.5 p.u. and $Q_{s}^{*}=0$. (b) Experimental waveforms showing transient response of $i_{s}$ due to step change in $P_{s}^{*}$ from 0 to -0.5 p.u. and $Q_{s}^{*}=0$. (c) Experimental waveforms showing steady-state waveforms of $i_{s}$ and $u_{s}$.

Transient in active power for a step change in $P^{*}$ from 0 to -0.5 p.u. is shown in Fig. 10(a). $Q^{*}$ is maintained at 0 . As $P^{*}$ is changed $P_{\text {err }}$ goes out of the prescribed band of 0.05 p.u. This results in the selection of only the active vectors thereby effecting the fastest possible change in $P^{*}$. The rate of change of $P_{s}$ is decided by the rate of change of rotor current which in turn depends on the dc link voltage. It may be noted from these waveforms, that, the transient responses in $P_{s}$ and $Q_{s}$ are perfectly decoupled. The steady-state ripple in $P_{s}$ and $Q_{s}$ due to switching between the positive and negative error bands can also be observed. Fig. 10(b) illustrates the effect of the active power transient as reflected in the stator current waveform. The steady-state current waveform in Fig. 10(c) clearly shows unity power factor operation.

The steady-state stator voltage and current waveforms for subsynchronous and synchronous operation are given in

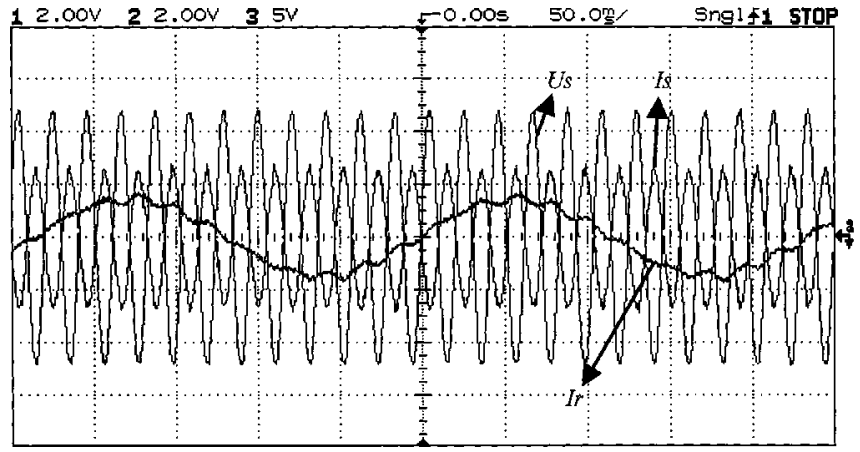

(a)

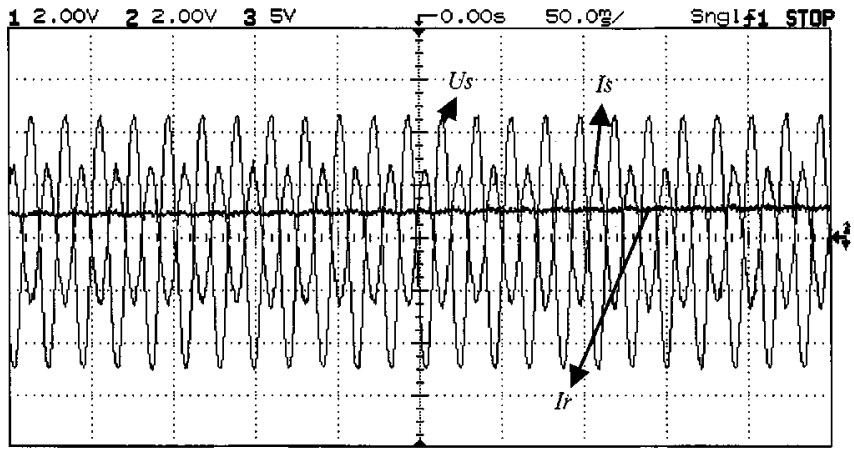

(ab)

Fig. 11. (a) Experimental results showing steady-state waveforms $u_{s}, i_{s}$, $i_{r}$ for $P_{s}^{*}=-0.5$ p.u., $Q_{s}^{*}=0$ at $1300 \mathrm{rpm}$ (subsynchronous operation). (b) Experimental results showing steady-state waveforms $u_{s}, i_{s}, i_{r}$ for $P_{s}^{*}=$ -0.5 p.u., $Q_{s}^{*}=0$ at $1430 \mathrm{rpm}$ (synchronous operation).

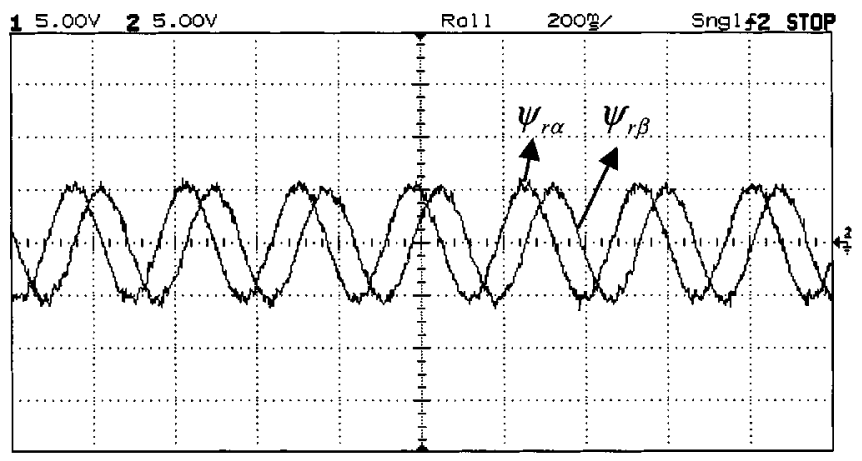

Fig. 12. Experimental results showing steady-state $\psi_{r a}, \psi_{r \beta}$ for $P_{s}^{*}=$ -0.25 p.u., $Q_{s}^{*}=0$.

Fig. 11(a) and (b) respectively. The synchronous speed operation is observed to be perfectly stable. In Fig. 12, the steadystate rotor flux waveforms $\psi_{r a}$ and $\psi_{r \beta}$ are presented.

Fig. 13(a) shows the steady-state waveforms of $P_{s}$ and $Q_{s}$ along with the sector information for $P_{s}^{*}=-0.5$ p.u. and $Q_{s}^{*}=$ 0 . (The sector information is scaled and output through DAC such that the analog output voltage is $1 \mathrm{~V}$ multiplied by the sector number.) For reliable detection of the direction of change of $Q_{s}$ a minimum switching period of six sampling periods (336 $\mu \mathrm{s})$ of a particular switching state is maintained. This also puts a maximum switching limit of $4.5 \mathrm{kHz}$ for the rotor side converter.

Fig. 13(b) gives the rotor current waveform along with the sector information for transition through synchronous speed. During subsynchronous speed operation, the flux vectors rotate in the positive direction in the rotor reference frame; hence 


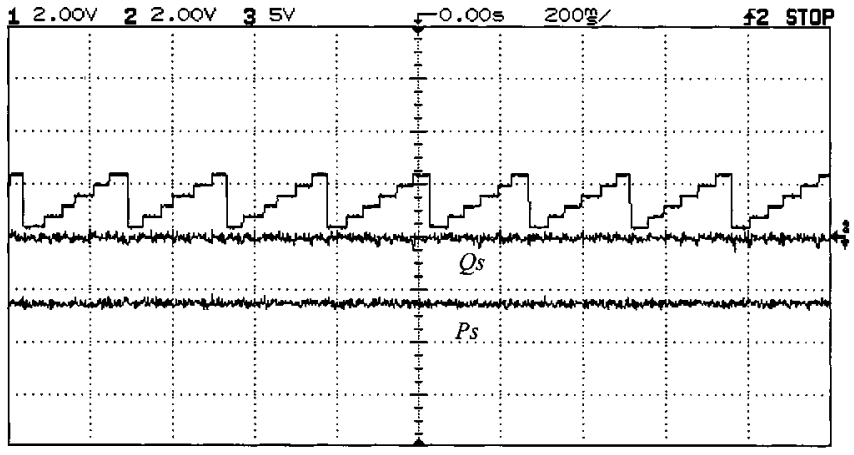

(a)

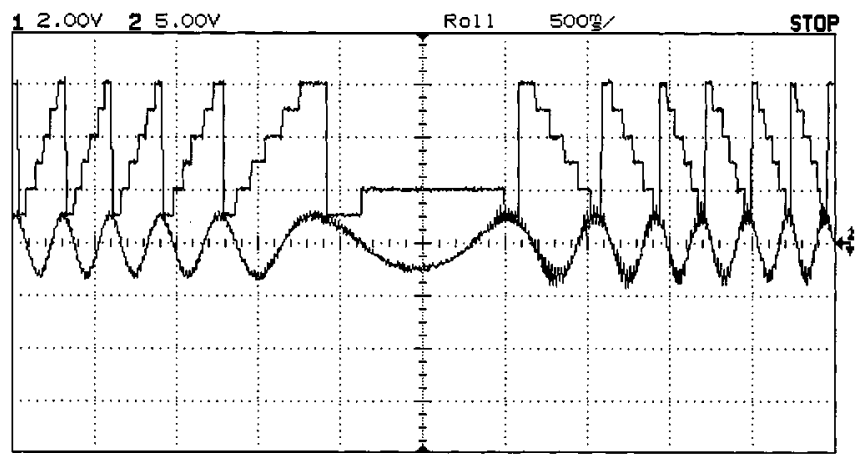

(b)

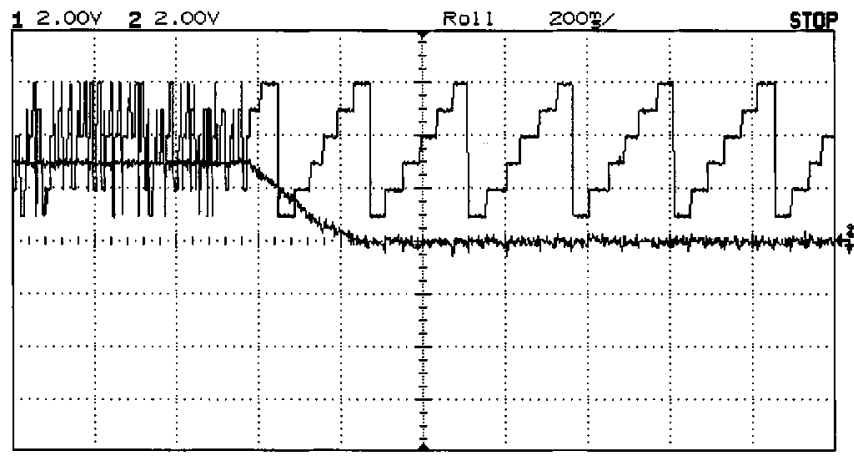

(c)

Fig. 13. (a) Experimental results showing $P_{s}, Q_{s}$ and sector information during steady-state operation with $P_{s}^{*}=-0.5$ p.u., $Q_{s}^{*}=0$ at $1300 \mathrm{rpm}$. (b) Experimental results showing $i_{r}$ and sector information during transition through synchronous speed. (c) Experimental results showing $Q_{s}$ and sector information during starting.

the sector number increases from 1 to 6 and resets back to 1 . This is represented by the ascending staircase waveform. As the rotor moves over to supersynchronous speed the flux vectors start rotating in the negative direction. Therefore, the sector number changes in the reverse order as seen by the descending staircase. The changeover from subsynchronous to supersynchronous speed is observed to be smooth without any transients in the rotor current waveform.

One of the important requirements for VSCF systems with restricted speed range is that the machines have to be "cut-in" when the shaft speed crosses a given limit. This is particularly important for applications like wind power generation. Before the rotor converter is switched on the entire reactive power is drawn from the stator side. Initially $Q_{s}^{*}$ is set to the computed value of $Q_{s}$ after passing it through a low-pass filter and $P_{s}^{*}$ is set to zero. The implication of this is that when the control is activated the rotor does not supply any active or reactive power; the machine simply floats on the bus. It is obvious that the sector computation will be incorrect before the control is released. Since the minimum switching period on the basis of which a definite decision about sector change is made is about $336 \mu \mathrm{s}$, the algorithm locks onto the correct sector within $1 \mathrm{~ms}$ $(336 \times 3)$ even if the actual sector is opposite to the computed sector at switch-on. The system can thus be started "on-the-fly" without any appreciable transient in rotor and stator currents. $Q_{S}^{*}$ is then slowly ramped down to zero (or any other reference) and the desired value of $P_{s}^{*}$ can be applied. The relevant waveforms of $Q_{s}$ and the computed sector are given in Fig. 13(c).

\section{CONCLUSION}

The proposed method is thus capable of controlling the active and reactive powers of a wound rotor induction machine without rotor position sensors. It offers excellent dynamic response and decoupled control of active and reactive powers as demonstrated by the simulation and experimental results. Since it depends only on voltage and current measurements on the stator side, it is insensitive to the parameters of the machine. The method used for identification of the sector in which the rotor flux is located avoids integration of PWM voltages and consequent errors. It can start "on-the-fly" and runs stably even at zero rotor frequency. The implementation of the algorithm on a digital controller is easy because of computational simplicity. The switching information is contained in small tables and therefore, the memory utilization is also economical. All these factors make the direct power control algorithm an attractive proposition for high performance sensorless control of wound rotor induction machines in industrial drives and VSCF applications like wind power generation.

\section{REFERENCES}

[1] W. Leonhard, Control of Electrical Drives. New York: SpringerVerlag, 1985, ch. 13.

[2] R. Pena, J. C. Clare, and G. M. Asher, "Doubly fed induction generator using back-to-back PWM converters and its application to variable-speed wind-energy generation," Proc. Inst. Elect. Eng., pt. B, vol. 143, pp. 231-241, May 1996.

[3] L. Xu and W. Cheng, "Torque and reactive power control of a doubly fed induction machine by position sensorless scheme," IEEE Trans. Ind. Applicat., vol. 31, pp. 636-642, May/June 1995.

[4] R. Datta and V. T. Ranganathan, "Decoupled control of active and reactive power for a grid-connected doubly-fed wound rotor induction machine without position sensors," in Proc. Conf. Rec. 1999 IEEE/IAS Anu. Meeting, 1999, pp. 2623-2630.

[5] L. Morel, H. Godfroid, A. Mirzaian, and J. M. Kauffmann, "Double-fed induction machine: Converter optimization and field oriented control without position sensor," Proc. Inst. Elect. Eng., pt. B, vol. 145, pp. 360-368, July 1998.

[6] E. Bogalecka, "Power control of a double fed induction generator without speed or position sensor," in Proc. Conf. Rec. EPE Brighton, vol. 8, ch. 50, 1993, pp. 224-228.

[7] M. Depenbrock, "Direct self control (DSC) of inverter-fed induction machine," IEEE Trans. Power Electron, vol. 3, pp. 420-429, Oct. 1988.

[8] I. Takahashi and T. Noguchi, "A new quick response and high efficiency control strategy of an induction motor," IEEE Trans. Ind. Applicat., vol. IA-22, pp. 820-827, Sept./Oct. 1986.

[9] I. Takahashi and Y. Ohmori, "High performance direct torque control of an induction motor," IEEE Trans. Ind. Applicat., vol. 25, pp. 257-264, Mar./Apr. 1989. 
[10] R. Datta and V. T. Ranganathan, "Method for direct control of active and reactive power from the rotor side for a grid connected doubly-fed slip-ring induction machine without position encoder," Indian Patent 797/MAS/99, June 8, 1999

[11] R. Datta, "Rotor side control of grid-connected wound rotor induction machine and its application to wind power generation," Ph.D dissertation, Dept. Elect. Eng., Indian Inst. Sci., Bangalore, India, Feb. 2000.

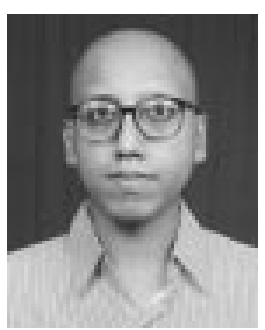

Rajib Datta received the B.E. degree in electrical engineering from Jadavpur University, Calcutta, in 1992, the M.Tech. degree in electrical engineering from the Indian Institute of Technology, Kharagpur, in 1994, and the Ph.D. degree from the Department of Electrical Engineering, Indian Institute of Science, Bangalore, in 2000.

From January 1995 to July 2000, he was a Research Scholar in the Department of Electrical Engineering, Indian Institute of Science, Bangalore. Presently, he is a Research Scientist at ABB, Corporate Research Center, Heidelberg, Germany. His research interests include power electronics, motor drives, and wind power generation.

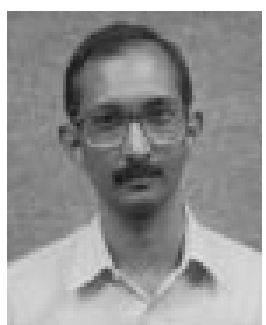

V. T. Ranganathan (SM' 84$)$ received the B.E. and M.E. degrees in electrical engineering from the Indian Institute of Science (I.I.Sc.), Bangalore, and the $\mathrm{Ph} . \mathrm{D}$. degree from Concordia University, Montreal, QC, Canada

He joined the Electrical Engineering Department, I.I.Sc., in 1984 and is currently a Professor. His research interests are in the area of power electronics and motor drives. He has published several papers in the areas of vector control of ac drives, pwm techniques, split phase induction motor drives, and rotor side control of slip ring induction motors. He is also a consultant to industry in the above areas and has participated in a number of projects.

Dr. Ranganathan received the Prize Paper Award of the IEEE-IAS Static Power Converter Committee and the Tata Rao Prize of the Institution of Engineers India. He is a fellow of the Institution of Engineers, India. 